\title{
PEDRO ALMODÓVAR Y EL UNIVERSO FEMENINO ANALIZADO A TRAVÉS DE SUS CARTELES CINEMATOGRÁFICOS.
}

\section{PEDRO ALMODOVAR AND THE FEMALE UNIVERSE ANALYZED THROUGH ITS FILM POSTERS}

\author{
AUTORA \\ María Tabuenca Bengoa \\ Profesora Doctora. Universidad CEU. Madrid (España). \\ maria.tabuencabengoa@ceu.es
}

\section{RESUMEN}

Desde su primera película Pedro Almodóvar permite que sean los personajes los vehículos de transmisión de sus ideas a través de las situaciones que representan; el cineasta reconoce que los protagonistas de las historias que el cuenta siguen siendo su mejor medio de expresión. Es por ello, que durante más de treinta años de carrera se ha venido decantando por volcar el grueso de la carga narrativa de sus creaciones sobre figuras femeninas.

A través del análisis del los carteles de aquellas películas en los que el elemento figurativo preponderante es o son mujeres y en cuyo título se hace alusión directa a ellas, se trata de mostrar la honda reflexión realizada por el director sobre el mundo que le rodea y sobre su visión del género femenino. Del mismo modo que las continuas tentativas de parodiar la iconografía tradicional, nos muestran la certeza 
de que el director está enamorado de las mujeres, de cualquier condición, estatus social o edad.

\section{PALABRAS CLAVE}

Pedro Almodóvar - Cartel - Femenino - Cine - Español.

\section{ABSTRACT}

From his first film Pedro Almodovar allows the characters are vehicles of transmission of ideas through the situations they represent the filmmaker acknowledges that the protagonists of the stories he tells are still his best means of expression. Therefore, that for more than thirty year career has been opted for dumping the bulk of the narrative charge of his creations on female figures. Through analysis of the posters of those films where the figurative element is dominant or women and whose title refers directly to them, is to show the deep reflections of the director about the world around him and his vision for the female gender. Just as the constant attempts to parody the traditional iconography, show us the certainty that the director is in love with women, whatever their condition, social status or age.

\section{KEY WORDS}

Pedro Almodovar - Poster - Female - Cine - Spanish

\section{ÍNDICE}

1. Vínculo entre Almodóvar y lo femenino.

2. Análisis del cartel de "Pepi, Luci, Bom y otras chicas del montón".

3. Análisis del cartel de "Mujeres al borde de un ataque de nervios".

4. Análisis del cartel de "Todo sobre mi madre". 
5. Análisis del cartel de "Hable con ella".

6. Conclusiones.

7. Bibliografía.

\section{Vínculo entre Almodóvar y lo femenino.}

A menudo se define a Pedro Almodóvar como un director de actrices, y es que realmente vive fascinado por el universo femenino, lo que lleva a que sus personajes principales sean casi siempre mujeres de fuerte personalidad, mientras que los hombres se presentan como seres débiles que desempeñan papeles meramente simbólicos. El director asegura que trata de defender a las mujeres y "aunque no cree que sean unos arcángeles, su corazón está siempre con ellas" (Vidal, 1990, p.35). $Y$, en efecto, se constata que los pocos hombres que aparecen en sus filmes no son merecedores del amor de las mujeres.

Ante la mera insinuación de un cierto atisbo de obsesión por su parte por el mundo femenino Almodóvar no duda en apuntar que no se trata de una obcecación, reconoce que sus películas están dominadas, tanto en cantidad como en calidad por personajes femeninos, ya que:

"Son más fuertes, más autónomos, se arriesgan más, son más dueñas de sus destinos, luchan mejor, tienen menos prejuicios, menos pudor. Sufren mejor, también. Y cuando sufren son más divertidas. Creo que todo eso es más que una fascinación por mi parte. Se debe a que las mujeres están más dotadas para vivir y manifestar que viven. Todos sentimos igual, pero a la hora de hacer cine me gusta más cómo manifiesta la mujer la soledad, los celos, porque es más activa. [...] 
Tal vez es una cuestión cultural, pero como sabéis García Lorca lo dijo hace muchos años: España es un país de actrices" (G. Hernández, 2004, pág. 49).

Sus películas muestran prototipos de mujer que representan esa querencia hacia una nueva modernidad de sociedad española. Sus personajes femeninos "fuertes $y$ positivos, a menudo en roles sociales más profesionales que los hombres" (García León, 1989, pág.81), ocupan normalmente puestos de mayor relevancia que sus parejas, mientras que ellos son policías o taxistas, ellas son yuppies, guapas e inteligentes, como la abogada feminista de Mujeres al borde de un ataque de nervios. El cine de Pedro Almodóvar plantea, por lo tanto, una visión androcéntrica de la sociedad, poniendo siempre el punto de mira en la mujer. En sus comienzos esto supuso una nueva perspectiva en la cinematografía española, que tendía a reflejar mayoritariamente un universo protagonizado por hombres, en el que la mujer no pasaba de ser más que un simple objeto.

El contrapunto a ello es Mujeres al borde de un ataque de nervios en la que se muestra una amplia gama de mujeres con diferentes caracteres y pertenecientes a distintas clases sociales; en ella no se rechaza el papel que los hombres juegan en sus vidas, el director simplemente "elige concentrarse en las interrelaciones y cómo cada una resuelve sus problemas, en gran medida independientemente de los hombres que las han oprimido" (Allinson, 2003, pág.109). A la hora de reflexionar acerca de la liberación de la mujer, Almodóvar comenta con cierta ironía que "la mujer ha evolucionado mucho, ha pasado de la batería de cocina a la batería de un grupo de rock y de ahí a una batería de artillería" (G. Hernández, 2004, pág.50).

Respecto de ciertos aspectos considerados tradicionalmente como algo negativo asociado a las féminas, - es el caso del histerismo, el nerviosismo o la inquietud-, el realizador mantiene que los nervios de las mujeres representan una fuerza "refrescante y liberadora que reta a una realidad deshumanizada" (G. Hernández, 2004, pág.50), llegando incluso a defender que "las mentes fragmentadas femeninas 
son las que permiten la creación de un nuevo espacio hecho de muchas piezas y alejado de la sociedad monolítica marginadora" (G. Hernández, 2004, pág. 50). De seguir la tendencia actual por el mismo camino, según la opinión del director manchego, la mujer podría llegar a controlar la sociedad pero "dudo que, afortunadamente, consiga controlar sus nervios. $Y$ este descontrol les honra porque significará que no han perdido su espontaneidad" (G. Hernández, 2004, pág. 50).

A Almodóvar le interesa la amistad entre mujeres como elemento dramático. Su complicidad, ya que las mujeres viven secretamente su intimidad y la comparten sólo con sus amigas. En su primera película, Pepi, Luci, Bom y otras chicas del montón, las chicas ya aparecen como seres autosuficientes que no dependen de los hombres para ser felices y se concluye que la amistad entre ellas tiene más importancia que el amor sexual.

La solidaridad es para el manchego una virtud reservada para el género femenino. Un aspecto fundamental que aparece en Tacones lejanos, donde se muestra la camaradería entre las reclusas de la cárcel, en Kika, para la que las amistades femeninas tiene un valor especial o en Todo sobre mi madre en la que la solidaridad entre mujeres se demuestra al máximo, mostrando la capacidad de ayudarse y comprenderse que ellas tienen en cualquier situación.

Tras la realización de La mala educación, en la que trabajó exclusivamente con hombres, pasó al rodaje únicamente con mujeres en Volver, una película mucho más divertida que el propio Almodóvar califica de analgésica. Respecto del trabajo con actores de su mismo sexo comenta que:

"Las películas que he hecho con hombres son mucho más áridas, más pesimistas, donde la emoción que te lleva es una emoción corrosiva y oscura. Por alguna razón, es evidente que mis películas con hombres son más implacables con los personajes. Si hablo de mi propio género 
Tabuenca Bengoa, María (2008): Pedro Almodóvar y el universo femenino analizado a través de sus carteles cinematográficos.

No 17. Noviembre. Año XII. Páginas: 1-16

ISSN: 1576-3420 DOI: http://dx.doi.org/10.15198/seeci.2008.17.1-16

10 que me atrae es lo más oscuro de mí mismo o del hombre en general" (Reviriego, 2006, pág.46).

A pesar de todo, Almodóvar expresa reiteradamente que para él "/o importante en sus personajes no es el género, sino el sentimiento" (G. Hernández, 2004, pág.50).

\section{Análisis del cartel de Pepi, Luci, Bom y otras chicas del montón (Ceesepe, 1980).}

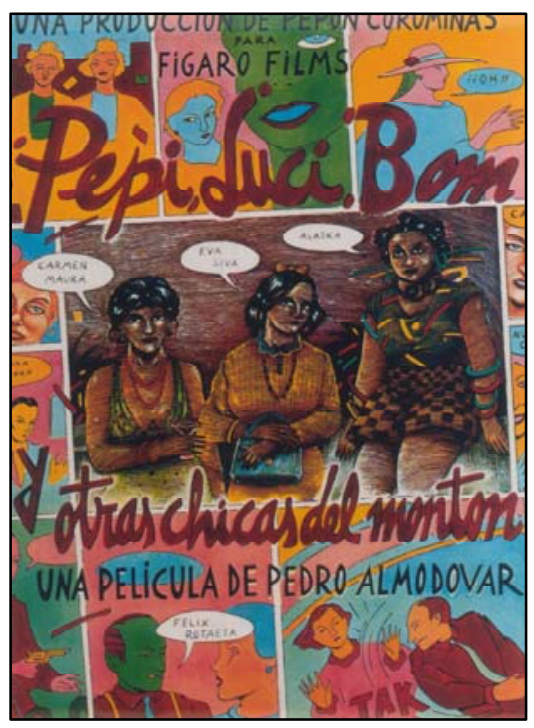

Desde el terreno del cómic llega Ceesepe "formado en los territorios del underground hispano" (Sánchez López, 1997, pág. 177), el cual realiza el cartel de la primera incursión seria de Almodóvar en el mundo del cine, Pepi, Luci, Bom y otras chicas del montón (1980). Tanto el cineasta como él mismo, procedían de un caldo de cultivo socio-cultural que se bautizó con el nombre de la Movida, un tiempo de explosión cultural asombrosamente fértil que adquirió envergadura artística y sociológica. 
Aborda el trabajo con el planteamiento en él habitual, plasmar una ilustración, en este caso un cómic de influencia pop, que sirva de fondo a todo el cartel. Mediante dibujos realistas se desarrollan viñetas en las que se representa el universo tanto femenino como feminista de la película. El cartelista hijo de la citada Movida valiéndose de distintos tipos de trazos y tratamiento del color, crea figuras quizá demasiado detalladas para el minimalismo característico que iría puliéndose en la siguiente década.

Dentro del formato vertical $(70 \times 100 \mathrm{~cm}$.) del cartel, el título, con tipografía de escritura desenfadada, aparece partido con la intencionalidad de realzar la viñeta central. En este trabajo se valora la frase publicitaria, con una ocupación del 4\% respecto de la superficie total del póster, mientras que el resto de los rótulos quedan dispersos en la composición y muy reducidos en espacio a tenor de lo que suele ser habitual.

El autor coloca a las protagonistas del filme en un dibujo central, dejando en los laterales espacio para completar la creación con escenas que aluden a la trama de la película. El gravitar de todo el diseño de la composición en torno a la viñeta central, debido a su situación, tamaño y resolución, produce una sensación visual de relieve cuya lejanía no sólo queda puesta de manifiesto por los trazos sino también por la paleta de colores.

Cromáticamente está realizado en vivos colores que alternan los matices en tonos cálidos de la gama de los marrones, rojizos, amarillos y tierras, con los fríos azules y verdosos, dando lugar a sensaciones encontradas de frescor y alegría con otras de tristeza y preocupación. La percepción de los blancos, tanto en los bocadillos de diálogo de los personajes como en los recuadros que enmarcan las viñetas, posibilita una clara definición del contenido icónico.

El resultado obtenido es muy afín al de un tebeo cuya tendencia kitsch refleja una caótica concepción de un cartel complejo e incluso raramente combinado, que podría 
conducir a equívocos en tanto en cuanto no termina de clarificar a qué género pertenece ni a qué público va dirigido.

\section{Análisis del cartel de Mujeres al borde de un ataque de nervios (Gatti, 1988).}

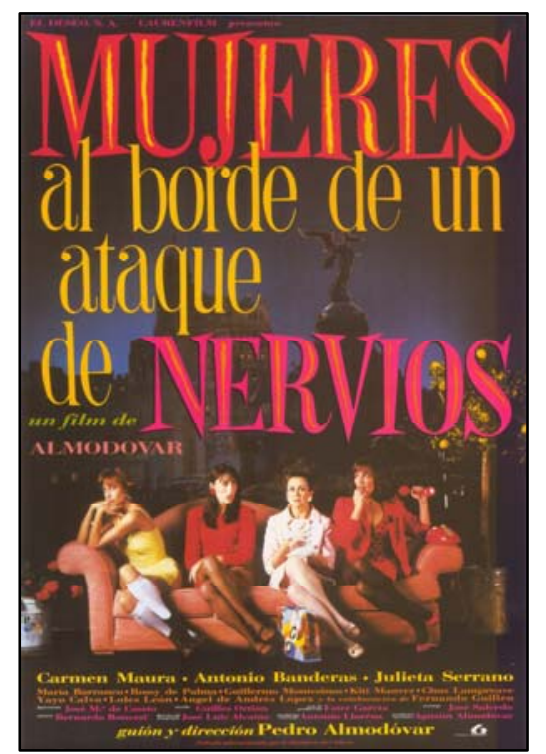

Con el diseño de este póster cambia el panorama de la cartelística de Almodóvar, ya que a partir de este momento y salvo en una ocasión, todos los diseños son proyectados y ejecutados por el estudio de Juan Gatti, argentino galardonado en el 2005 con el Premio Nacional de Diseño de España que otorga el Ministerio de Industria, Turismo y Comercio, ya que el jurado valoró la personalidad que a lo largo de su carrera le ha sabido dar al ejercicio de la profesión gráfica. Su trabajo ha destacado por una gran sensibilidad y por un valor cultural que trasciende su probada solvencia profesional. Más que ilustrador, diseñador gráfico, director de arte o fotógrafo Juan Gatti se define como un creador de imágenes que usa distintas 
técnicas, al que no le gusta encasillarse en ninguna de ellas lo que supone un enriquecimiento definitivo en la estética y en la gráfica del realizador manchego.

En este caso, incluso, se opta por la realización de varias versiones del cartel, sin contar las confeccionadas por las distribuidoras para el mercado internacional, con las que satisfacer el afán de diversificación que plantea toda la obra de Almodóvar y a modo de continuación de su inconfundible visión de un mundo lleno de cambios y multiplicado por sí mismo. Sobra decir que todas ellas tienen como base el espíritu feminista, eje argumental de la película.

Desarrollado en un formato vertical ( $69 \times 99 \mathrm{~cm}$.), y con un marcado criterio realista, el diseñador argentino plantea una composición estructurada en tres zonas horizontales articuladas sobre un fondo general, remarcado en todo su perímetro por un filete blanco. Para ello se sirve de una composición fotográfica basada en personajes, escenarios y símbolos alusivos a la cinta.

Abarcando algo más de la mitad del cartel se encuentra el título con la escueta frase publicitaria, utilizando para remarcar los conceptos más característicos del filme tanto la tipografía como el tamaño de las letras y el color; así aparecen las letras con remate cambiando al tipo de fantasía para las palabras más significativas. Ocupando toda la parte inferior $\mathrm{y}$, sirviendo como base del contenido gráfico, se ordenan el resto de los rótulos con letras de tipo romana moderna. Con Gatti la tipografía gana espacio a la imagen y la constriñe, de forma que el título no sólo evoca un estado de ánimo, sino que sirve para acotar unos límites estéticos y cinematográficos que remiten al cartelismo americano propio de los años sesenta.

La parte icónica del cartel recae en la imagen de un sofá donde se encuentran los personajes principales posando y junto a elementos que dan pistas al espectador sobre los caracteres de cada uno de ellos, y como telón de fondo está la 
escenografía de la azotea de la protagonista, excusa que el director utiliza para ofrecer la visión más kitsch de la ciudad de Madrid.

Cromáticamente, además del fondo fotográfico de la panorámica urbana coloreada en tonos azules oscuros que transmiten profundidad, incertidumbre y sorpresa, el diseño propone una foto en color de las protagonistas, cuya secuencia refleja una gran complicidad. Por otro lado, los colores rojo, amarillo y fucsia de los rótulos destacan sobre el resto, transmitiendo toda una variedad de connotaciones psicológicas que van desde la vitalidad a la violencia, pasando por las envidias y los celos.

En el caso de las otras versiones planteadas para publicitar la película, en una de ellas Gatti opta por jugar con recortes de revistas que muestran unos labios y unas piernas de mujer ataviada a la moda de los 70 , mientras que en el otro prefiere dividir el póster en dos partes colocando una multiplicación de diferentes rostros femeninos.

\section{Análisis del cartel de Todo sobre mi madre (Mariné, 1999).}

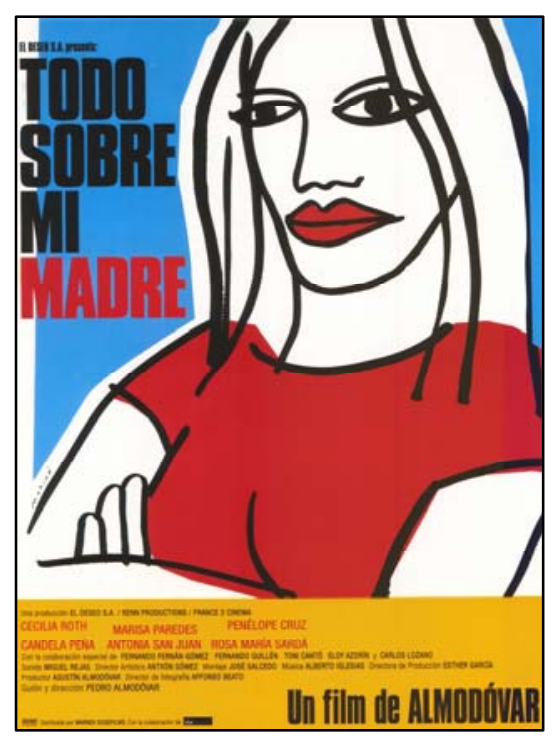


El póster realizado para la publicidad de Todo sobre mi madre, uno de los carteles de Almodóvar más reconocibles tanto a nivel nacional como internacional, casualmente no está realizado por su diseñador de cabecera habitual, el fotógrafo argentino J uan Gatti; en esta ocasión el elegido es el ilustrador madrileño Oscar Mariné que consigue realizar un cartel que ha sabido convertirse en un símbolo del director manchego.

Surgido del mundo de la publicidad, sobresaliente y polivalente diseñador cuya historia originaria discurre paralelamente a la Movida madrileña, en la que su personal concepción del diseño alimentó aventuras como la revista contracultural Madrid Me Mata, Mariné pasó de ser el diseñador gráfico icono del underground de los ochenta a un reputado profesional apasionado con cada proyecto.

La imagen creada por Mariné para Todo sobre mi madre (1999) surgió tras un proceso de diseño que duró casi un año; junto con el director entabló una relación muy intensa fruto de su complicidad y se pusieron como meta la realización de un cartel especial. Durante ese tiempo exploraron diferentes caminos y opciones compositivas, por lo que el hecho de que el cartel seleccionado finalmente fuera un dibujo de Mariné fue algo casi accidental ya que tenían otros diez carteles diferentes preparados y no había ninguna posibilidad de fallo.

La lámina elegida para la publicidad de Todo sobre mi madre, es aquella que consigue sintetizar el trabajo de un creador que es capaz de expresar muchas ideas con pocos trazos. El póster en cuestión consiguió exportarse a las salas de cine de todo el mundo sin que sufriera variación alguna en su diseño, algo que sucedía por vez primera en la historia del cine español, lo que tuvo como resultado que dicho cartel haya sido uno de los símbolos españoles más reconocidos mundialmente.

En un formato vertical $(68,5 \times 92,5 \mathrm{~cm}$.), el artista español diseña un cartel realista que tiene en cuenta los aspectos típicos del arte y del cartelismo, en el que el 
marcado trazo del dibujo y los colores puros consiguen transmitir un mensaje atractivo y rotundo de claridad.

Se trata de un diseño sencillo y efectivo en el que se muestra la imagen de una figura humana, desde lo que se conoce en el lenguaje cinematográfico como un plano medio, es decir cortada a la altura del pecho. El dibujo de esta mujer imprime al diseño un carácter femenino totalizador, al igual que sucede con el argumento de la película, en la que todo el peso argumental recae sobre el universo femenino, lo que en términos generales supone un homenaje a las mujeres.

Dicho cartel está estructurado en tres áreas bien definidas: una superior izquierda, un faldón enfatizado por una trama de color y el resto. El contenido textual, compuesto totalmente en letra de palo seco sin modulación, queda colocado en el cuadrante superior izquierdo alineado en bandera derecha, lo que equilibra compositivamente el elemento icónico, mientras que el resto se posiciona abarcando todo el faldón. Proporcionalmente, los textos ocupan el $21 \%$ de la superficie del cartel, lo cual denota el interés del autor por la ilustración antes que por los elementos textuales secundarios.

En lo que a la carga icónica se refiere, el único y principal elemento que aparece en la composición es un boceto pintado en colores pasionales, tan queridos por Almodóvar, de la cabeza y el torso de una mujer, de una madre. Referenciada con trazo grueso y por el color rojo tanto en el texto como en el elemento icónico, las connotaciones femeninas impactan visualmente al espectador atendiendo a las dimensiones del retrato, pese a tratarse de un sencillo boceto ilustrativo.

Desde el punto de vista cromático, el número de colores empleados es tres, en tintas de texturas planas, todos ellos están directamente relacionados con los contenidos argumentales de la película. Por un lado, la excitación, la fuerza y la pasión del rojo; de otro, la alusión al mundo de los sueños, la amistad y la vida eterna del azul turquesa; y, como complemento, la ira, la emoción y la traición representadas por el 
amarillo cadmio. Así, mientras el rojo rellena zonas del icono remarcadas por trazos negros, más concretamente la boca (un elemento facial con tantas insinuaciones que más adelante Gatti recupera en Volver y Los abrazos rotos), el azul se utiliza como fondo del texto del título y el amarillo a modo de trama sobre la que descansan tanto la frase publicitaria como el resto de los rótulos.

La elección de Mariné por la trilogía rojo-blanco-azul no es del todo casual, sino más bien una elección subliminal de cara a la participación de la película en el Festival de Cannes. Un guiño estratégico que Almodóvar puede permitirse al ser el mercado francés su principal foco de alabanzas y consumo.

\section{ANÁlisis del CARTEL de "HABLE CON ELLA" (GATTI, 2001)}

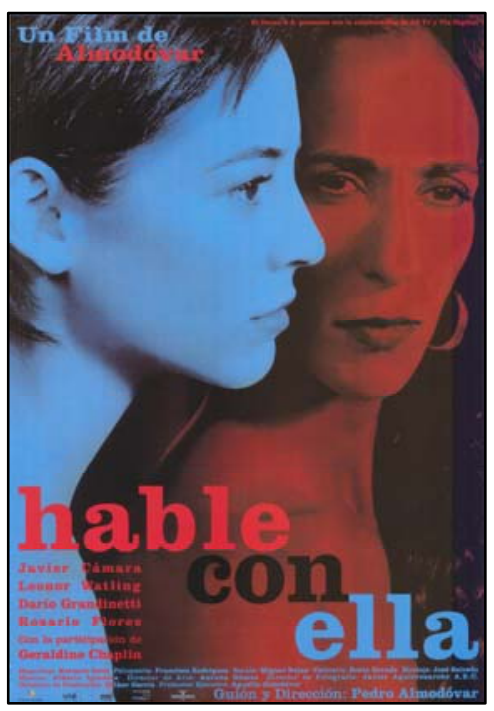

El triunfo internacional obtenido con la película anterior $\mathrm{y}$, por ende, del anterior cartel, no une profesionalmente por más tiempo a Oscar Mariné y Almodóvar. Con Hable con ella se materializa el reencuentro del cineasta con el polifacético Juan 
Gatti, que regresa para encargarse del diseño de los carteles que publicitan las cintas más controvertidas del director.

A partir de una gran composición fotográfica en la que se muestra a dos de los protagonistas del filme, el diseñador argentino plantea un concluyente cartel realista de formato vertical $(68,5 \times 99,5 \mathrm{~cm}$.), estructurado a partir de dos grandes áreas verticales definidas por el posicionamiento del elemento icónico.

De manera que se interfiera lo menos posible en las imágenes, el diseñador va situando la carga textual en las zonas más residuales del cartel, haciendo especial hincapié sobre las tres líneas en las que el título partido queda suspendido de forma escalonada. Se ha optado por buscar una lectura clara y precisa para lo que se ha utilizado una tipografía egipcia a base de letras de remate grueso que provoca gran impacto por su determinación y a una posición escalonada de las palabras que forman el título, lo que obliga a su lectura direccional. La ocupación del texto es muy reducida, tan sólo del $17 \%$, reflejando con ello la clara intencionalidad del autor de situar todo el protagonismo en la imagen.

Los elementos icónicos transmiten facetas de los caracteres de las personalidades a través de las posiciones de las tomas de las protagonistas, de manera que a la sensibilidad de una foto de lado se le contrapone la dureza de una instantánea frontal en la que no se termina de enfocar la mirada de la protagonista directamente al objetivo de la cámara. Con este juego de perfiles se intenta recrear la incomunicación que se vive entre las parejas, eje fundamental de la trama.

Resuelto con la utilización de filtros de colores rojo y azul para alterar cromáticamente la fotografía original, la composición del cartel denota una pretendida discordancia algo estridente que consigue atraer la atención, manteniéndola para y posteriormente proceder a su análisis. En la elección de los tonos seleccionados para el diseño de este sofisticado póster están aglutinadas las 
alusiones a la amistad, la pasión, la muerte y la soledad, todos ellos elementos que conforman un argumento maduro, espinoso pero de una sensibilidad extrema.

Con este filme se perpetuaba el gusto del director por la tragedia y, la compleja recreación cinéfila cada vez se aleja más de la vulgaridad y de la simplicidad. Sus películas se caracterizan por guardar diferentes niveles de comprensión no todos ellos aptos para la totalidad del público. Todos esos rasgos son perceptibles en el diseño de un póster que emplea la combinación de los colores complementarios rojo y el azul, una obsesión permanente del director manchego y que se obtienen a partir de la combinación del color primario con su secundario opuesto en el círculo cromático.

\section{Conclusiones}

Por último, consideramos interesante cerrar este estudio apuntando que Almodóvar se considera feminista y en su obra, si bien a veces se utilizan símbolos de una sociedad dominada por los hombres, es tan sólo para alterarlos y con ellos expresar "una genuina identificación con lo «femenino»" (G. Hernández, 2004, pág.50). Podemos comprobar cómo con ello no se pretende dar a entender que en sus películas siempre se representen imágenes femeninas positivas, ya que algunas veces es así, y otras todo lo contrario; pero de lo que no hay duda, es de que "ridiculizan estereotipos y denuncian la falacia de la construcción de géneros orquestada por una sociedad patriarcal" (G. Hernández, 2004, pág.50).

Por lo tanto, se puede afirmar que el cineasta se subleva contra las construcciones ideológicas impuestas que marginan y se revela

"ante las máscaras creando nuevas máscaras, ante las filosofías que engañan, ante los intentos tiránicos de la razón que quieren instaurar 
la causa prima, e incorpora, en sus obras, la fuerza creativa $y$ liberadora del deseo «femenino»"(G. Hernández, 2004, pág.50).

\section{Bibliografía}

ALLINSON, Mark. (2003). Un laberinto español. Las películas de Pedro Almodóvar. Ocho y medio, Libros de Cine. Madrid.

G. HERNÁNDEZ, María. (2004). Estilos decadentes, deseos "femeninos": Nietze, Lorca, Almodóvar. Libertarias, Madrid.

G. LEÓN, María Antonia y MALDONADO, Teresa. (1989). Pedro Almodóvar; la otra España Cañí. Biblioteca de Autores y Temas Manchegos. Ciudad Real.

REVIRIEGO, Carlos (2006): "Almodóvar" en Revista El Cultural, no16 de Abril, Pág. 45-48.

REVIRIEGO, Carlos (2009): "Luces en la oscuridad" en Revista Cahiers du cinema, no21, Pág. 14.

SÁNCHEZ LÓPEZ, Roberto (1997). El cartel de cine. Arte y Color. Prensas Universitarias de Zaragoza. Zaragoza.

VIDAL, Nuria. (2000). El cine de Pedro Almodóvar. Ediciones Destino. Barcelona. 